\title{
Stent-Assisted Coiling versus Coiling Alone in Unruptured Intracranial Aneurysms in the Matrix and Platinum Science Trial: Safety, Efficacy, and Mid-Term Outcomes
}

S.W. Hetts, A. Turk, J.D. English, C.F. Dowd, J. Mocco, C. Prestigiacomo, G. Nesbit, S.G. Ge, J.N. Jin, K. Carroll, Y. Murayama, A. Gholkar, S. Barnwell, D. Lopes, S.C. Johnston, and C. McDougall, on behalf of the Matrix and Platinum Science Trial Investigators

\begin{abstract}
BACKGROUND AND PURPOSE: Stent-assisted coiling may result in less aneurysm recanalization but more complications than coiling alone. We evaluated outcomes of coiling with and without stents in the multicenter Matrix and Platinum Science Trial.
\end{abstract}

MATERIALS AND METHODS: All patients in the Matrix and Platinum Science Trial with unruptured intracranial aneurysms treated per protocol were included. Baseline patient and aneurysm characteristics, procedural details, neurologic outcomes, angiographic outcomes, and safety data were analyzed.

RESULTS: Overall, 137 of 361 (38\%) patients were treated with a stent. Stent-coiled aneurysms had wider necks ( $\geq 4 \mathrm{~mm}$ in $62 \%$ with stents versus $33 \%$ without, $P<.0001$ ) and lower dome-to-neck ratios (1.3 versus 1.8, $P<.0001)$. Periprocedural serious adverse events occurred infrequently in those treated with and without stents (6.6\% versus $4.5 \%, P=.39)$. At 1 year, total significant adverse events, mortality, and worsening of $\mathrm{mRS}$ were similar in treatment groups, but ischemic strokes were more common in stent-coiled patients than in coiled patients $(8.8 \%$ versus $2.2 \%, P=.005)$. However, multivariate analysis confirmed that at 2 years after treatment, prior cerebrovascular accident (OR, $4.7 ; P=.0089)$ and aneurysm neck width $\geq 4 \mathrm{~mm}(\mathrm{OR}, 4.5 ; P=.02)$ were the only independent predictors of ischemic stroke. Stent use was not an independent predictor of ischemic stroke at 2 years (OR, 1.1; $P=.94)$. Stent use did not predict target aneurysm recurrence at 2 years, but aneurysm dome size $\geq 10 \mathrm{~mm}(\mathrm{OR}, 9.94 ; P<.0001)$ did predict target aneurysm recurrence.

CONCLUSIONS: Stent-coiling had similar outcomes as coiling despite stented aneurysms having more difficult morphology than coiled aneurysms. Increased ischemic events in stent-coiled aneurysms were attributable to baseline risk factors and aneurysm morphology.

ABBREVIATIONS: MAPS = Matrix and Platinum Science Trial; TAR $=$ target aneurysm recurrence

A $\mathrm{s}$ intracranial aneurysm treatment has shifted in the past 30 years from exclusively surgical to predominantly endovascular, aneurysm morphologies once considered untreatable endovascularly are now treatable with coils, stents, and flow diverters. ${ }^{1-3}$ Particularly for saccular aneurysms with broad necks and short domes, stent-assisted coiling has become a common technique. ${ }^{4-8}$ Prior studies have reported that stent-coiling may result

Received May 23, 2013; accepted after revision August 5.

From the Departments of Radiology and Biomedical Imaging (S.W.H., C.F.D.) and Neurology (S.C.J.), University of California, San Francisco, San Francisco, California; Department of Radiology (A.T.), Medical University of South Carolina, Charleston, South Carolina; Departments of Neurology and Radiology (J.D.E.), California Pacific Medical Center, San Francisco, California; Department of Neurosurgery (J.M.), Vanderbilt University Medical Center, Nashville, Tennessee; Department of Neurosurgery (C.P.), University of Medicine and Dentistry of New Jersey, Newark, New Jersey; Department of Radiology (G.N., S.B.), Oregon Health and Science University, Portland, Oregon; Department of Biostatistics (S.G.G., J.N.J.), Stryker Neurovascular (K.C.), Fremont, California; Department of Neurosurgery (Y.M.), Jikei University, Tokyo, Japan; Department of Neuroradiology (A.G.), Newcastle Upon Tyne Hospital, Newcastle Upon Tyne, United Kingdom; Department of Neurosurgery (D.L.), Rush University Medical Center, Chicago, Illinois; and Department of Neurosurgery (C.M.), Barrow Neurological Institute, Phoenix, Arizona. in less aneurysm recanalization over time but more complications - both intraprocedurally and in a delayed fashion - than coiling alone. ${ }^{9-13}$ A recent large, single-institution, retrospective series described higher morbidity and mortality rates associated with the stent-coiling technique as compared with coiling either with or without balloon assistance. ${ }^{14}$

Given that prospective data on stent-coiling are limited, we analyzed data from the prospective, randomized, multicenter Matrix and Platinum Science (MAPS) Trial (NCT00396981, www. clinicaltrials.gov). The MAPS Trial was primarily designed to determine whether polymer-modified coils or platinum bare metal coils result in lower aneurysm recanalization, lower aneurysm rupture or rerupture, or lower aneurysm retreatment. Although patients were

Please address correspondence to Steven W. Hetts, MD, Interventional Neuroradiology, 505 Parnassus Ave, L-352, San Francisco, CA 94143-0628; e-mail: steven.hetts@radiology.ucsf.edu

- Indicates open access to non-subscribers at www.ajnr.org

三 Indicates article with supplemental on-line table.

http://dx.doi.org/10.3174/ajnr.A3755 


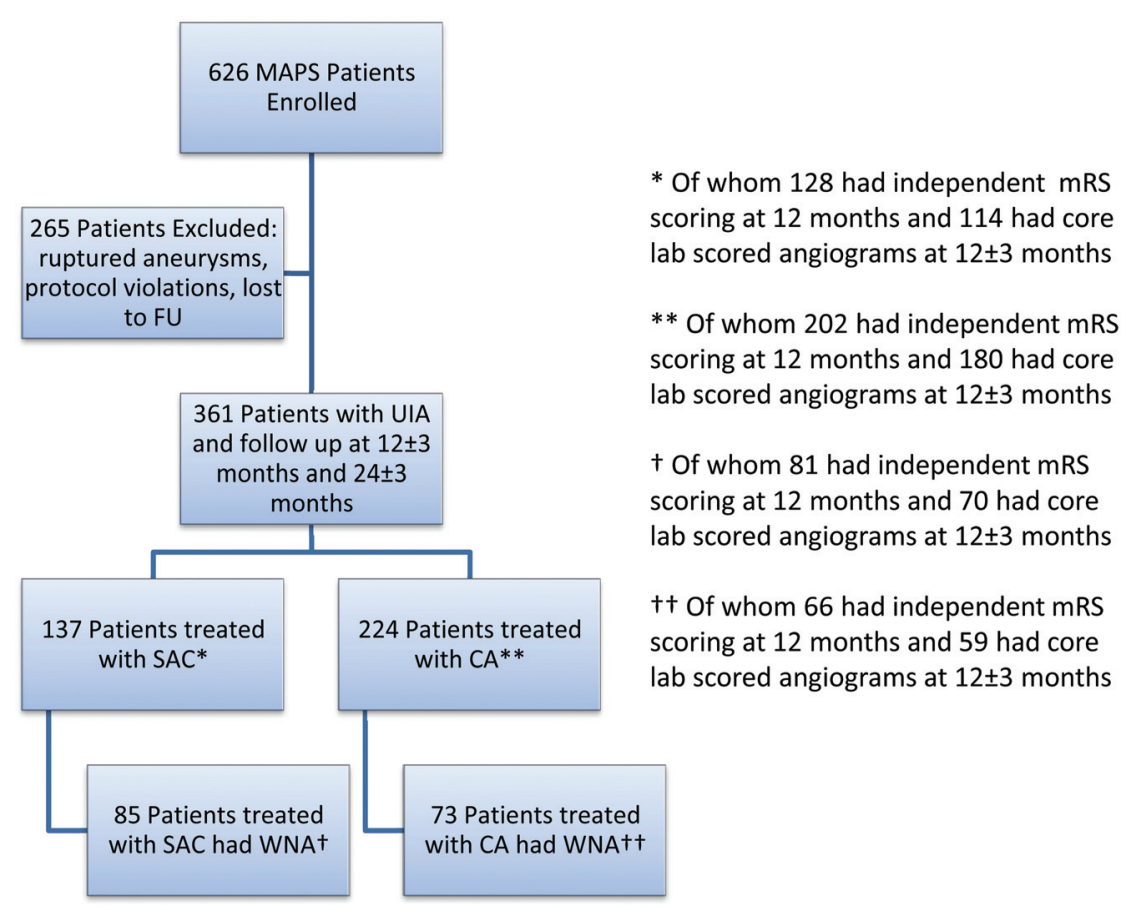

FIG 1. Patient flow for MAPS stent substudy. FU indicates follow-up; UIA, unruptured intracranial aneurysm; SAC, stent-assisted coiling; CA, coiling alone; WNA, wide-neck aneurysm.

\section{Study Subjects}

The study population for the current analysis included subjects $18-80$ years of age with a baseline $\mathrm{mRS}$ score of $0-3$ who had a single documented, untreated, unruptured intracranial aneurysm (4-20 $\mathrm{mm}$ in maximum dimension on DSA) for which both polymer modified coils (Matrix2, Stryker Neurovascular, Fremont, California) and platinum bare metal coils (GDC, Stryker Neurovascular) were treatment options and for which primary coiling treatment was planned to be completed during a single procedure. Stent placement (Neuroform stent, Stryker Neurovascular), as a separate preliminary procedure antecedent to the primary coiling, was allowed, as was stent placement in conjunction with the primary coiling procedure. Although the overall MAPS Trial prospectively enrolled patients with ruptured and unruptured aneurysms, only patients with unruptured aneurysms were included in the present post hoc data analysis.

We chose to analyze the unruptured randomly assigned to platinum bare metal coil or polymer-modified coil implantation, adjunctive devices (including balloons and stents) could be used in any case at the discretion of the operating physician.

We compared baseline patient and aneurysm characteristics, procedural details, safety data, neurologic outcomes, and angiographic outcomes in MAPS patients with unruptured intracranial aneurysms who were treated with stent-coiling or coiling without stent placement. Additionally, we analyzed results for the subset of patients with wide-neck aneurysms.

\section{MATERIALS AND METHODS}

The MAPS Trial was conceived and designed by the investigators, with advice provided by the sponsor, and was approved by all local institutional review boards. The study was conducted in accordance with the International Conference on Harmonization (ICH) Good Clinical Practice (GCP): Consolidated Guideline, the Declaration of Helsinki, EN ISO14155 Clinical Investigations of Medical Devices for Human Subjects, and the applicable regulations from the US Food and Drug Administration. The primary end point of the MAPS Trial was target aneurysm recurrence (TAR), designed to be a clinically relevant composite end point that comprised aneurysm rupture after treatment, retreatment, or death from an unknown cause. The trial was designed to study the TAR rate for the study device and to investigate how TAR correlated with the angiographic surrogates that are widely used in endovascular aneurysm treatment studies to evaluate outcomes. Clinical and angiographic evaluations were completed at the time of initial aneurysm treatment and within $12 \pm 3$ months after initial aneurysm treatment. Further clinical follow-up of subjects by telephone interview will continue annually until 5 years after initial aneurysm treatment. aneurysm cohort because the stent-coiling technique is primarily applied in clinical practice to patients with unruptured aneurysms. The administration of dual antiplatelet medications typically indicated in stent-coiling is relatively contraindicated in patients with ruptured aneurysm who might need additional interventions such as ventricular drain placement. On this basis, all patients with ruptured aneurysms in the MAPS trial were excluded from our current analysis, consisting of 6 patients treated with stent-coiling and 201 patients treated with coiling (Fig 1).

A total of 361 patients in the MAPS Trial with unruptured intracranial aneurysms were treated per protocol. Data were analyzed post hoc for all unruptured intracranial aneurysms and for the wide-neck ( $\geq 4 \mathrm{~mm}$ ) aneurysm subgroup of unruptured intracranial aneurysms. Note that because this is a post hoc analysis of the MAPS Trial, patients were not randomly assigned to stentcoiling or coiling and may be dissimilar, especially within the cohort including all unruptured intracranial aneurysms.

As defined above, the primary outcome measure was TAR. Secondary outcome measures, all defined a priori, included angiographic assessment as assessed by enrolling sites and core imaging laboratory; neurologic assessments (mRS at $12 \pm 3$ months and as change from baseline performed in-person by an independent certified practitioner at a scheduled clinic visit); and technical procedural success, defined as the successful placement of coils in the target aneurysm. Target aneurysm reintervention was defined as any further treatment of the aneurysm, with the retreatment decision being at the discretion of the operator.

All sites graded their own angiographic outcomes on the basis of the modified 3-point Raymond Scale after the procedure and at follow-up. ${ }^{15-17}$ All sites also recorded an assessment of perceived change from baseline (same, better, worse) at follow-up. Digitized 
copies of the angiograms were created for all cases and stored at an independent angiographic core laboratory located at the University of California, San Francisco. The core laboratory assessed all treatment and 1-year follow-up angiograms blinded to the treatment technique. Core laboratory evaluations used the same angiographic scales as did the enrolling sites. All angiographic data presented in this analysis are from core laboratory evaluations performed by 2 neurointerventionalists, with adjudication of differences in angiographic scoring by a third neurointerventionalist. ${ }^{17}$ The core laboratory also evaluated angiograms of patients with wide-neck aneurysms receiving stent-coiling specifically for any stent migration between immediate postprocedure DSA and follow-up DSA.

An independent steering committee was responsible for overall oversight of the science and execution of the trial. Patient safety data were reviewed at regular intervals by an independent Data Monitoring Committee. An independent Clinical Events Committee was responsible for reviewing and adjudicating all deaths and neurologic events. On-site monitoring and source document verification of case report forms against original patient records were completed for more than $40 \%$ of patients at the completion of the 1-year follow-up, including all patients who had been treated with stent-coiling.

\section{Statistical Methods}

The primary end point (TAR) rate was calculated by use of Kaplan-Meier estimates in each group at the end of a $12 \pm 3$-month window (455 days) and a $24 \pm 3$-month window (820 days). Time to event was based on the real time to rupture/rerupture, retreatment, or unknown cause of death, whichever happened first for each subject. Subjects who had not had an event were censored at their last clinical visit or at 820 days, whichever came earlier.

The protocol prespecified additional univariate and multivariate regression models to analyze the time to TAR, changes in mRS from baseline to the 12-month assessment, and subgroup analyses. Additional post hoc multivariate regression analysis was performed to evaluate the contribution of baseline risk factors, aneurysm characteristics, and use of stents to stroke rates and target aneurysm recurrence. Complete data on ischemic stroke and TAR rates were included in predictor analyses, including data from all enrolling centers.

A Student $t$ test was used to test distributions of continuous variables between the groups. Either $\chi^{2}$ or the Fisher exact test was used to analyze binary variables according to standard statistical practice. For ordinal variables, such as the mRS, recanalization, and mRS scores, the Wilcoxon rank sum test was used to test the distribution between the groups. The differences between the groups were presented with the $95 \%$ CI estimated by the normal approximation. For the binary outcomes, the relative risks as well as its 95\% CIs were also presented. All statistical analyses were performed with the use of SAS, version 9.2 (SAS Institute, Cary, North Carolina).

\section{RESULTS}

Of 626 patients in the MAPS Trial, overall, 361 with unruptured intracranial aneurysms were treated per protocol (Fig 1). Of these
361 patients with unruptured intracranial aneurysms, 137 were treated with a Neuroform stent and either platinum bare metal coils or polymer modified coils (stent-coiling group) and 224 were treated with platinum bare metal coils or polymer modified coils without a stent (coiling group). Within the unruptured intracranial aneurysm cohort, 158 patients had wide-neck aneurysms with necks $\geq 4 \mathrm{~mm}$ in diameter (wide-neck aneurysm subset). Within this wide-neck aneurysm subset, 85 patients received stent-coiling and 73 received coiling. Because stent use was at the operating physician's discretion on a case-by-case basis, some enrolling sites used many stents and some used none (Fig 2). Stent use was particularly inhomogeneous geographically: $88.3 \%$ of stent-coiling cases were performed in North American centers versus $65.6 \%$ of coiling cases without stent use $(P=.0001$, Table 1).

\section{Baseline Demographics}

Patients with stent-coiling trended toward being sicker at baseline than did coiling patients in the entire unruptured intracranial aneurysm cohort (Table 1), with coronary artery disease in 19\% of stent-coiling versus $13.1 \%$ of coiling $(P=.14)$. Coronary artery disease was significantly more frequent among the patients with stent-coiling with wide-neck aneurysms $(22.4 \%)$ as compared with patients with wide-neck aneurysms treated with coiling (5.6\%, $P=.003)$. Prior stroke was also marginally more frequent in the patients with stents and coils $(17.9 \%)$ versus the patients with coils alone in the wide-neck aneurysms $(8.3 \%, P=.08)$. Otherwise, both groups were similar at baseline.

\section{Aneurysm Characteristics}

Aneurysms in the stent-coiling group had more technically challenging morphologies than those in the coiling group (Table 2). Among unruptured intracranial aneurysms, $62 \%$ of stent-coiling versus $33 \%$ of coiling were wide-neck aneurysms $(P<.0001)$, and the dome-to-neck ratio was lower for stent-coiling than for coiling (1.3 versus $1.8, P<.0001)$. Among wide-neck aneurysms, patients receiving stent-coiling had smaller aneurysms (maximum dimension $>10 \mathrm{~mm}$ in $30.6 \%$ versus $47.9 \%, P=.03$ ), with larger necks (mean, 5.6 versus $5.0 \mathrm{~mm} ; P=.004$ ), and lower dome-to-neck ratios ( 1.2 versus $1.6, P<.0001)$. In both the overall unruptured intracranial aneurysm cohort as well as the wideneck aneurysm subset, aneurysms treated with stent-coiling were less likely to be located on the circle of Willis than those treated with coiling.

\section{Procedural Characteristics}

Among patients with unruptured intracranial aneurysms, the stent-coiling procedure took slightly longer than did the coiling procedure (mean, 134.2 versus 117.8 minutes; $P=.02$ ). This time difference was not significant in the more technically challenging wide-neck aneurysm subset (mean, 147.5 versus 135.2 minutes; $P=.30$ ) (Table 3).

For unruptured intracranial aneurysms, coil packing attenuation trended higher with stent-coiling $(26.2 \%$ versus $24.2 \%, P=$ .07). Among wide-neck aneurysms, packing attenuation for stentcoiling was higher than packing attenuation for coiling without stent placement $(26.4 \%$ versus $21.1 \%, P=.002)$ despite a trend 


\section{Enrollment by Site - SAC vs. CA}

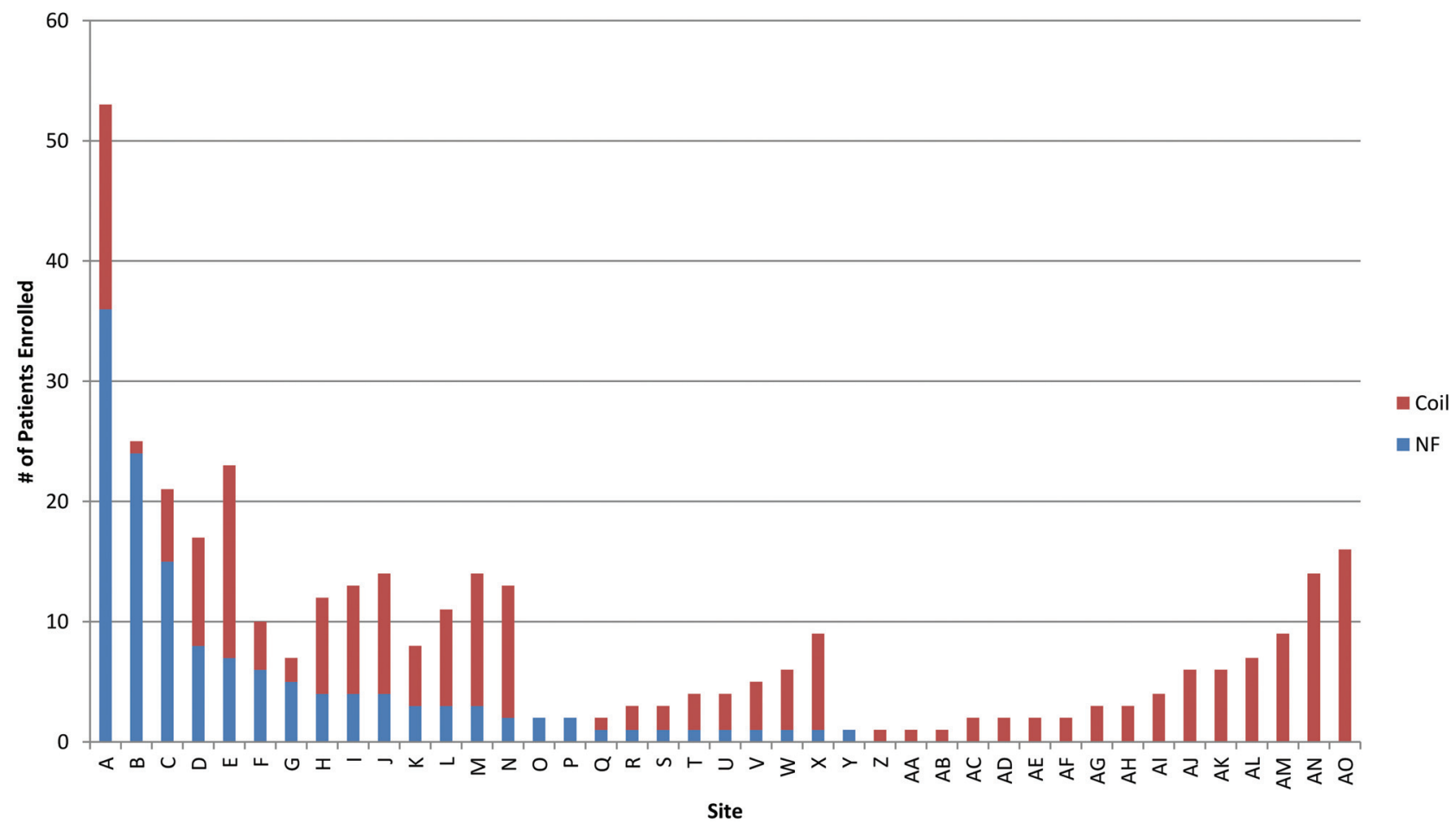

FIG 2. Stent use by enrolling site. SAC indicates stent-assisted coiling, CA, coiling alone, NF, Neuroform stent.

Table 1: Baseline patient demographics

\begin{tabular}{|c|c|c|c|c|c|c|}
\hline & \multicolumn{3}{|c|}{ All Unruptured Aneurysms } & \multicolumn{3}{|c|}{ Wide-Neck Aneurysms } \\
\hline & Stent-Coil $(n=137)$ & Coil Alone $(n=224)$ & $P$ Value & Stent-Coil $(n=85)$ & Coil Alone $(n=73)$ & $P$ Value \\
\hline North American & $88.3 \%$ & $65.6 \%$ & .0001 & $89.4 \%$ & $61.6 \%$ & $<.0001$ \\
\hline Age, y & 56.5 & 56.7 & .90 & 58.4 & 57.7 & .68 \\
\hline Female & 76.6 & 76.8 & .98 & 72.9 & 79.5 & .34 \\
\hline Coronary artery disease & $19.0 \%$ & $13.1 \%$ & .14 & $22.4 \%$ & $5.6 \%$ & .003 \\
\hline$\geq 2$ Cerebrovascular risk factors $^{a}$ & $32.1 \%$ & $25.9 \%$ & .20 & $34.1 \%$ & $26.0 \%$ & .27 \\
\hline Prior CVA & $16.9 \%$ & $14.5 \%$ & .54 & $17.9 \%$ & $8.3 \%$ & .08 \\
\hline \multicolumn{7}{|l|}{ Preprocedure mRS } \\
\hline 0 & $80.3 \%$ & $84.4 \%$ & $>.99$ & $80.0 \%$ & $90.4 \%$ & NA \\
\hline 1 & $15.3 \%$ & $11.6 \%$ & & $14.1 \%$ & $9.6 \%$ & \\
\hline 2 & $4.4 \%$ & $3.6 \%$ & & $5.9 \%$ & $0.0 \%$ & \\
\hline 3 & $0.0 \%$ & $0.4 \%$ & $>.99$ & $0.0 \%$ & $0.0 \%$ & NA \\
\hline
\end{tabular}

Note:-CVA indicates cerebrovascular accident; NA, not applicable.

${ }^{a}$ Cerebrovascular risk factors include hypertension, hyperlipidemia, coronary artery disease, and diabetes mellitus.

Table 2: Aneurysm characteristics

\begin{tabular}{|c|c|c|c|c|c|c|}
\hline & \multicolumn{3}{|c|}{ All Unruptured Aneurysms } & \multicolumn{3}{|c|}{ Wide-Neck Aneurysms } \\
\hline & Stent-Coil $(n=137)$ & Coil Alone $(n=224)$ & $P$ Value & Stent-Coil $(n=85)$ & Coil Alone $(n=73)$ & $P$ Value \\
\hline Maximum dimension & 7.6 & 7.8 & .46 & 8.9 & 10.1 & .007 \\
\hline Height is $\max$ & $43.8 \%$ & $54.9 \%$ & .04 & $42.4 \%$ & $50.7 \%$ & .30 \\
\hline Width is max & $29.9 \%$ & $21.4 \%$ & .07 & $30.6 \%$ & $23.3 \%$ & .30 \\
\hline Depth is max & $26.3 \%$ & $23.7 \%$ & .58 & $27.1 \%$ & $26.0 \%$ & .88 \\
\hline Max dimension $>10 \mathrm{~mm}$ & $19.7 \%$ & $21.0 \%$ & .77 & $30.6 \%$ & $47.9 \%$ & .03 \\
\hline Neck $\geq 4 \mathrm{~mm}$ & $62.0 \%$ & $32.6 \%$ & $<.0001$ & $100 \%$ & $100 \%$ & NA \\
\hline Average neck & 4.7 & 3.5 & $<.0001$ & 5.6 & 5.0 & .004 \\
\hline Dome/neck radio & 1.3 & 1.8 & $<.0001$ & 1.2 & 1.6 & $<.0001$ \\
\hline Dome/parent artery ratio & 2.0 & 2.1 & .33 & 2.2 & 2.6 & .01 \\
\hline Circle of Willis location & $44.5 \%$ & $64.7 \%$ & .0002 & $48.2 \%$ & $72.6 \%$ & .002 \\
\hline
\end{tabular}

Note:-Max indicates maximum.

toward use of fewer coils (8.5 mean versus 10.1 mean, $P=.07$ ). Overall technical success was high for all groups but marginally lower for stent-coiling in the unruptured intracranial aneurysm cohort $(97.8 \%)$ as compared with coiling in the unruptured intracranial aneurysm cohort $(100 \%, P=.054)$. Among unruptured intracranial aneurysms, complete angiographic obliteration 


\begin{tabular}{|c|c|c|c|c|c|c|}
\hline & \multicolumn{3}{|c|}{ All Unruptured Aneurysms } & \multicolumn{3}{|c|}{ Wide-Neck Aneurysms } \\
\hline & Stent-Coil $(n=137)$ & Coil Alone $(n=224)$ & $P$ Value & Stent-Coil $(n=85)$ & Coil Alone $(n=73)$ & $P$ Value \\
\hline Aspirin alone & $8.0 \%$ & $23.2 \%$ & .0002 & $4.7 \%$ & $28.8 \%$ & $<.0001$ \\
\hline Clopidogrel alone & $5.1 \%$ & $4.5 \%$ & .78 & $3.5 \%$ & $1.4 \%$ & 0.62 \\
\hline Aspirin + clopidogrel & $78.1 \%$ & $37.1 \%$ & $<.0001$ & $82.4 \%$ & $37.0 \%$ & $<.0001$ \\
\hline Antiplatelet use not recorded ${ }^{a}$ & $8.8 \%$ & $35.3 \%$ & $<.0001$ & $9.4 \%$ & $32.9 \%$ & .0003 \\
\hline Procedure time, min & 134.2 & 117.8 & .02 & 147.5 & 135.2 & .30 \\
\hline No. of coils & 6.9 & 7.1 & .70 & 8.5 & 10.1 & .07 \\
\hline Bare metal coils & $49.6 \%$ & $50.9 \%$ & .82 & $48.2 \%$ & $53.4 \%$ & .52 \\
\hline Matrix coils & $50.4 \%$ & $49.1 \%$ & .82 & $51.8 \%$ & $46.6 \%$ & .52 \\
\hline Packing density & $26.2 \%$ & $24.0 \%$ & .07 & $26.4 \%$ & $21.1 \%$ & .002 \\
\hline Technical success & $97.8 \%$ & $100 \%$ & .054 & $97.6 \%$ & $100 \%$ & .50 \\
\hline \multicolumn{7}{|l|}{ Occlusion assessment } \\
\hline Raymond 1 & $21.1 \%$ & $33.9 \%$ & $.02^{\mathrm{b}}$ & $18.6 \%$ & $27.1 \%$ & $.25^{c}$ \\
\hline Raymond 2 & $25.4 \%$ & $25.6 \%$ & $.98^{\mathrm{b}}$ & $27.1 \%$ & $30.5 \%$ & $.67^{c}$ \\
\hline Raymond 3 & $53.5 \%$ & $40.6 \%$ & $.03^{\mathrm{b}}$ & $54.3 \%$ & $42.4 \%$ & $.18^{\mathrm{c}}$ \\
\hline
\end{tabular}

${ }^{a}$ No antiplatelet use recorded in these subjects: for an individual subject, this could mean no aspirin or clopidogrel was used or that data are missing.

${ }^{\mathrm{b}}$ Core lab occlusion assessment for the $81 \%$ of patients who had assessable angiograms after the procedure.

${ }^{c}$ Core lab occlusion assessment for the $82 \%$ of patients who had assessable angiograms after the procedure.

Table 4: Safety: Stroke and Other Significant Adverse Events

\begin{tabular}{|c|c|c|c|c|c|c|}
\hline & \multicolumn{3}{|c|}{ All Unruptured Aneurysms } & \multicolumn{3}{|c|}{ Wide-Neck Aneurysms } \\
\hline & Stent-Coil $(n=137)$ & Coil Alone $(n=224)$ & $P$ Value & Stent-Coil $(n=85)$ & Coil Alone $(n=73)$ & $P$ Value \\
\hline $\begin{array}{l}\text { Periprocedural significant adverse } \\
\text { event rate }\end{array}$ & $6.6 \%$ & $4.5 \%$ & .39 & $3.7 \%$ & $0.89 \%$ & .11 \\
\hline 1-Year hemorrhagic stroke rate & $2.9 \%$ & $0.4 \%$ & .07 & $2.4 \%$ & $0.0 \%$ & .50 \\
\hline $\begin{array}{l}\text { 1-Year ischemic stroke rate } \\
\text { if problem site is excluded }\end{array}$ & $8.8 \%$ & $2.2 \%$ & .005 & $11.8 \%$ & $4.1 \%$ & .08 \\
\hline 1-Year ischemic stroke rate & $6.2 \%$ & $2.2 \%$ & .11 & $8.8 \%$ & $4.1 \%$ & .31 \\
\hline
\end{tabular}

${ }^{a}$ One enrolling site accounted for 5 of 12 subjects with ischemic stroke in the unruptured aneurysm group. All ischemic strokes at that site occurred $\geq 7$ days after the procedure.

Table 5: Safety: $\mathrm{mRS}$ at baseline and 1 year after the procedure

\begin{tabular}{|c|c|c|c|c|c|c|c|c|c|c|}
\hline \multirow[b]{3}{*}{ 12-Month mRS ${ }^{a}$} & \multicolumn{5}{|c|}{ All Unruptured Aneurysms } & \multicolumn{5}{|c|}{ Wide-Neck Aneurysms } \\
\hline & \multicolumn{2}{|c|}{ Stent-Coil } & \multicolumn{2}{|c|}{ Coil Alone } & \multirow[b]{2}{*}{$P$ Value } & \multicolumn{2}{|c|}{ Stent-Coil } & \multicolumn{2}{|c|}{ Coil Alone } & \multirow[b]{2}{*}{$P$ Value } \\
\hline & $\begin{array}{c}\text { Base } \\
(n=137)\end{array}$ & $\begin{array}{c}1 \text { Year } \\
(n=128)\end{array}$ & $\begin{array}{c}\text { Base } \\
(n=224)\end{array}$ & $\begin{array}{c}1 \text { Year } \\
(n=202)\end{array}$ & & $\begin{array}{c}\text { Base } \\
(n=85)\end{array}$ & $\begin{array}{c}1 \text { Year } \\
(n=81)\end{array}$ & $\begin{array}{c}\text { Base } \\
(n=73)\end{array}$ & $\begin{array}{c}1 \text { Year } \\
(n=66)\end{array}$ & \\
\hline 0 & $80.3 \%$ & $80.5 \%$ & $84.4 \%$ & $87.6 \%$ & & $80.0 \%$ & $80.2 \%$ & $90.4 \%$ & $92.4 \%$ & \\
\hline 1 & $15.3 \%$ & $14.1 \%$ & $11.6 \%$ & $6.9 \%$ & & $14.1 \%$ & $12.3 \%$ & $9.6 \%$ & $6.1 \%$ & \\
\hline 2 & $4.4 \%$ & $1.6 \%$ & $3.6 \%$ & $1.0 \%$ & & $5.9 \%$ & $2.5 \%$ & $0.0 \%$ & $0.0 \%$ & \\
\hline 3 & $0.0 \%$ & $1.6 \%$ & $0.4 \%$ & $2.5 \%$ & & $0.0 \%$ & $2.5 \%$ & $0.0 \%$ & $1.5 \%$ & \\
\hline 6 & $0.0 \%$ & $2.3 \%$ & $0.0 \%$ & $2.0 \%$ & & $0.0 \%$ & $2.5 \%$ & $0.0 \%$ & $0.0 \%$ & \\
\hline mRS worse than base & & $12.5 \%$ & & $8.4 \%$ & .23 & & $13.6 \%$ & & $4.5 \%$ & .06 \\
\hline
\end{tabular}

a Twelve-month mRS scores were available for 128, 202, 81, and 66 patients, respectively, across all subsets.

of aneurysm filling at the conclusion of treatment was lower for stent-coiling than for coiling $(21.1 \%$ versus $33.9 \%, P=.02)$. Although a similar trend was present in the wide-neck aneurysm subset, it did not reach statistical significance. Dual-antiplatelet use at the time of treatment was higher for stent-coiling than for coiling because it is the practice of most centers to use both aspirin and clopidogrel at the time of stent-coiling and for a variable period thereafter.

\section{Safety: Stroke, Other Significant Adverse Events, and Neurologic Disability}

Although total periprocedural significant adverse events did not differ between stent-coiling and coiling ( $6.6 \%$ versus $4.5 \%, P=.39)$, the rate of stroke within 1 year of treatment did differ between these groups ( $8.8 \%$ versus $2.2 \%$, respectively; $P=.005$, Table 4 ). Of note, $42 \%$ of stent-coiling ischemic strokes occurred at one enrolling site, the exclusion of which brings the comparative ischemic stroke rates to $6.2 \%$ versus $2.2 \%$, respectively $(P=.11)$. Within the wide-neck aneurysm subgroup, there was no significant difference in ischemic stroke rates between stent-coiling and coiling, though there was a trend toward more ischemia in the stented patients $(P=.08)$. Among all patients with unruptured intracranial aneurysms, 1-year hemorrhagic strokes also trended toward a higher rate in the stent-coiling group $(2.9 \%)$ compared with the coiling group $(0.4 \%, P=.07)$. At 1 year, total significant adverse events, mortality, and worsening of $\mathrm{mRS}$ scores were not different between stent-coiling and coiling (Table 5) in the entire unruptured intracranial aneurysm cohort, though there was a trend toward worsening mRS scores in the wide-neck aneurysm subset $(P=.06)$.

Five stent-coiled patients had periprocedural strokes $(<7$ days after the procedure) and 7 stent-coiled patients had delayed strokes (On-line Table). Of the periprocedural strokes, one was thought related to preprocedure angioplasty or intraprocedure parent artery coil prolapse. A patient with extensive cardiovascular risk factors had both a periprocedural 
Table 6: Clinical outcomes 1 year after the procedure

\begin{tabular}{|c|c|c|c|c|c|c|}
\hline & \multicolumn{3}{|c|}{ All Unruptured Aneurysms } & \multicolumn{3}{|c|}{ Wide-Neck Aneurysms } \\
\hline & Stent-Coil $(n=137)$ & Coil Alone $(n=224)$ & $P$ Value & Stent-Coil $(n=85)$ & Coil Alone $(n=73)$ & $P$ Value \\
\hline TAR & $8.8 \%$ & $8.5 \%$ & .93 & $14.1 \%$ & $13.7 \%$ & .94 \\
\hline Delayed bleed & $0.0 \%$ & $0.4 \%$ & $<.99$ & $0.0 \%$ & $1.4 \%$ & .46 \\
\hline Retreatment & $8.8 \%$ & $8.5 \%$ & .93 & $14.1 \%$ & $13.7 \%$ & .94 \\
\hline
\end{tabular}

Table 7: Angiographic outcomes 1 year after the procedure

\begin{tabular}{|c|c|c|c|c|c|c|}
\hline & \multicolumn{3}{|c|}{ All Unruptured Aneurysms } & \multicolumn{3}{|c|}{ Wide-Neck Aneurysms } \\
\hline & Stent-Coil $(n=114)$ & Coil Alone $(n=180)$ & $P$ Value & Stent-Coil $(n=70)$ & Coil Alone $(n=59)$ & $P$ Value \\
\hline \multicolumn{7}{|c|}{ Occlusion assessment } \\
\hline Raymond 1 & $51.8 \%$ & $44.4 \%$ & .22 & $45.7 \%$ & $27.1 \%$ & .03 \\
\hline Raymond 2 & $21.1 \%$ & $23.9 \%$ & .57 & $17.1 \%$ & $30.5 \%$ & .07 \\
\hline Raymond 3 & $27.2 \%$ & $31.7 \%$ & .41 & $37.1 \%$ & $42.4 \%$ & .55 \\
\hline \multicolumn{7}{|c|}{ Change assessment } \\
\hline Better & $51.8 \%$ & $31.1 \%$ & .0004 & $45.7 \%$ & $20.3 \%$ & .003 \\
\hline Same & $31.6 \%$ & $35.6 \%$ & .48 & $32.9 \%$ & $28.8 \%$ & .62 \\
\hline Worse & $16.7 \%$ & $33.3 \%$ & .002 & $21.4 \%$ & $50.8 \%$ & .0005 \\
\hline
\end{tabular}

Note:- $81 \%$ of subjects in the "all unruptured aneurysms" group and $82 \%$ of subjects in the "wide-neck aneurysms" subgroup had angiograms assessable by the core lab at 1-year follow-up.

Table 8: Multivariate predictors of ischemic stroke at 1 year and 2 years

\begin{tabular}{lcccc}
\multicolumn{1}{c}{ Parameter } & 1-Year OR (95\% Cl) & 1-Year $\boldsymbol{P}$ Value & 2-Year OR (95\% Cl) & 2-Year $\boldsymbol{P}$ Value \\
\hline Prior cerebrovascular accident & $3.84(1.29-11.4)$ & .0159 & $4.71(1.47-15.0)$ & .0089 \\
Aneurysm neck size $\geq 4 \mathrm{~mm}$ & $3.70(1.09-12.5)$ & .0359 & $4.51(1.27-16.0)$ & .0196 \\
Stent used & $1.85(0.61-5.59)$ & .2732 & $1.05(0.34-3.27)$ & .9351 \\
\hline
\end{tabular}

Note:-Complete data on ischemic stroke rates were included in predictor analysis, including data from all enrolling centers.

Table 9: Multivariate predictors of target aneurysm recurrence at 1 year and 2 years

\begin{tabular}{lcccr}
\multicolumn{1}{c}{ Parameter } & 1-Year OR (95\% Cl) & 1-Year $\boldsymbol{P}$ Value & 2-Year OR (95\% Cl) & 2-Year $\boldsymbol{P}$ Value \\
\hline Aneurysm dome size $\geq 10 \mathrm{~mm}$ & $10.1(4.06-24.9)$ & $<.0001$ & $9.94(4.12-24.0)$ & $<.0001$ \\
Aneurysm neck size $\geq 4 \mathrm{~mm}$ & $2.34(0.94-5.81)$ & .0664 & $2.17(0.93-5.06)$ & .0729 \\
Stent used & $0.89(0.38-2.10)$ & .7855 & $0.83(0.36-1.88)$ & .6505 \\
\hline
\end{tabular}

Note:-Complete data on target aneurysm recurrence rates were included in predictor analysis, including data from all enrolling centers.

stroke and a myocardial infarction and died. Three patients had delayed strokes after documented or suspected antiplatelet medication noncompliance. One patient each had a delayed stroke after hernia surgery, after aneurysm retreatment, and after surveillance angiography. One patient with a basilar tip aneurysm had a pontine infarct thought to be related to small-vessel ischemic disease.

\section{Outcomes at 1 Year and 2 Years}

Clinical outcomes at 1 year and 2 years, on the basis of the primary MAPS composite end point of TAR, were similarly excellent in stent-coiling and coiling patients in the unruptured intracranial aneurysm cohort as well as in the wide-neck aneurysm subset (Table 6). Only a single patient from the coiling group had aneurysm rupture; all remaining TAR events were aneurysm retreatments at the discretion of the operating physician.

Complete angiographic obliteration rates for stent-coiling were significantly higher than for coiling in the wide-neck aneurysm subset at 1 year (Raymond 1 occlusion, $45.7 \%$ versus $27.1 \%$, $P=.03$ ) (Table 7). Angiographic worsening (on the better-sameworse scale comparing $12 \pm 3$-month follow-up angiograms with immediate posttreatment angiograms) was lower for stent-coiling than for coiling in both the unruptured intracranial aneurysm (16.7\% versus $33.3 \%, P=.002)$ and wide-neck aneurysm groups (21.4\% versus $50.8 \%, P=.0005)$. Concomitantly, angiographic improvement at 1 year in treated aneurysms was more common for stent-coiling versus coiling in the unruptured intracranial aneurysm cohort (51.8\% versus $31.1 \%, P=.0004)$ as well as in the wide-neck aneurysm subset $(45.7 \%$ versus $20.3 \%, P=.003$ ). Core lab analysis revealed no significant stent migration at 1 year. Because angiographic follow-up was not mandated as part of the trial beyond $12 \pm$ 3 months, 2-year angiographic data were not collected.

\section{Multivariate Analysis of Stroke and TAR}

The higher ischemic stroke rate in patients receiving stents was attributable to a higher proportion of stent-coiling patients having a baseline history of cerebrovascular accident and a higher proportion of stent-coiling patients having aneurysms with wide necks (Table 8) both at 1 year and 2 years after treatment. TAR, which consisted almost entirely of aneurysm retreatments, was predicted by baseline aneurysm morphologic characteristics, including dome $\geq 10 \mathrm{~mm}$ and neck $\geq 4 \mathrm{~mm}$, at both 1 year and 2 years of follow-up (Table 9). Stent use was not an independent predictor of TAR.

\section{DISCUSSION}

Self-expanding stents have greatly broadened the range of aneurysm morphologies amenable to endovascular treatment. Although the MAPS Trial was designed to evaluate polymer modified coils versus platinum bare metal coils, it allows us to analyze high-quality prospective data on patient outcomes after stent-coiling.

AJNR Am J Neuroradiol 35:698-705 Apr 2014 www.ajnr.org 703 
There was a high technical success rate for both stent-coiling and coiling. Stent-coiling was used more frequently in aneurysms with morphologies that typically limit the use of coils because of the risk of parent artery coil prolapse, including low dome-to-neck ratios and wide aneurysm necks. Aneurysm neck $\geq 4 \mathrm{~mm}$ has been associated with a higher risk of aneurysm recanalization ${ }^{18,19}$; in the MAPS Trial, all 12 stent-coiled aneurysms and 10 of 19 coiled aneurysms retreated within 1 year had necks $\geq 4 \mathrm{~mm}$ (Table 6). Conversely, no stentcoiled aneurysms with a $<4$-mm neck (and only $4 \%$ of coiled aneurysms with $<4$-mm neck) were retreated within 1 year. Wide-neck stent-coiled aneurysms also had higher packing densities, perhaps because the stent lessens concern for parent artery coil prolapse. ${ }^{20}$ This higher packing attenuation may explain why wide-neck stentcoiled aneurysms had superior aneurysm occlusion (Raymond Scale scores) at 1 year as compared with wide-neck coiled aneurysms.

Although stent-coiled aneurysms had worse Raymond occlusion scores immediately after treatment than did coiled aneurysms in both the total unruptured intracranial aneurysm cohort and the wide-neck aneurysm subset, they also had more improvement in angiographic appearance at follow-up. There are 4 possible explanations. First, starting with worse initial angiograms will bias follow-up readings on the better-same-worse scale toward more improvement. Second, procedural dual-antiplatelet use is significantly more frequent in stent-coiled patients; therefore it is possible that more interstitial filling is present immediately after treatment in stent-coiled patients as compared with coiled patients. Third, stents were used in more morphologically challenging aneurysms than in the coiled group, and it may not have been possible to treat these aneurysms without a stent. For example, in a very broad-neck, low-domed, shallow aneurysm, it might be difficult to herniate coils into the proximal and distal corners of the aneurysm neck even with a stent in place; such aneurysms could not have been treated with coils alone. Fourth, stents may help to prevent coil compaction within an adjacent aneurysm, perhaps directly by acting as partial parent artery flow diverters, or indirectly by allowing practitioners to confidently pack more coils into stented aneurysms (especially at the neck), or by providing a scaffold for endothelialization across the neck. Because angiographic appearance on follow-up significantly influences aneurysm retreatment decisions and initial core laboratory angiographic score predicts retreatment at 1 year ( $\mathrm{McD}$ ougall et al, AJNR in press), it will be important to determine how well immediate posttreatment aneurysm occlusion ultimately predicts aneurysm retreatment over the course of the entire MAPS Trial.

Although periprocedural total significant adverse events were low and similar in stent-coiled and coiled patients, the higher delayed ischemic stroke rate observed in stent-coiled patients is concerning. It is reassuring, however, that multivariate analysis including patients from all enrolling centers confirms that this increased stroke risk is attributable to the presence of more patients in the stent-coiled group having a history of cerebrovascular accident and the presence of more wide-neck aneurysms in the stent-coiled group, as opposed to being caused by stent use per se. Other investigators have reported increased thromboembolic events with the use of intracranial stents in the treatment of aneurysms. ${ }^{14}$ Whenever metal is placed in the parent artery, use of antiplatelet agents such as aspirin and/or clopidogrel is prudent to reduce platelet aggregation before the stent becomes endothelialized. Many centers use dual-antiplatelet medications (eg, aspirin and clopidogrel) for either a specified period of time after intracranial stent deployment (eg, 6 weeks or 6 months), until a follow-up angiogram, or indefinitely. Practitioner variability in postprocedure antiplatelet medication may significantly influence delayed ischemic risk to stent patients. This is suggested by poor patient antiplatelet compliance accounting for at least 3 of 12 ischemic strokes in the stentcoiled group and 3 additional ischemic strokes taking place immediately around the time of surgery, aneurysm retreatment, and follow-up angiography, during which antiplatelet medication regimens were uncertain (On-line Table). In addition to medication compliance and lack of consensus on antiplatelet regimen after intracranial stent placement, studies also suggest that inherent biologic resistance to the effects of aspirin and/or clopidogrel may also play a role in delayed ischemic events. ${ }^{21}$

The primary goal of aneurysm treatment is to prevent subarachnoid hemorrhage. Given the very low hemorrhage rate (1 of 361 patients within 2 years), it is too soon to speculate on the overall utility of stent-coiling compared with coiling in protecting patients with unruptured intracranial aneurysms from aneurysm rupture. Not surprisingly, aneurysm dome size $\geq 10 \mathrm{~mm}$ predicted TAR, possibly as the result of the greater opportunity for coil compaction in large aneurysms.

There are several limitations to our study. First, this is a post hoc data analysis from a prospective trial designed to evaluate polymer modified coils versus platinum bare metal coils, not stent-coiling versus coiling. Therefore, stent use was at the operating physician's discretion. Some centers used many stents and some used none. Stent use was significantly higher in North America as opposed to outside North America, suggesting that other geography-specific confounders may be present. Second, some aneurysm morphologies probably could not be treated with coiling alone and could only be treated with stent-coiling, thus biasing stent-coiling cases toward aneurysms with particularly wide necks and low dome-to-neck ratios, known predictors of aneurysm recanalization and procedural complications. Third, postprocedure antiplatelet medication management was not uniform. Because the delayed ischemic stroke rate for stent-coiling may be associated with antiplatelet management, this is a significant limitation. Fourth, the core angiographic laboratory could not score almost $20 \%$ of angiograms, most frequently because of image quality, nonmatched comparison views between immediate posttreatment and follow-up, and lack of digital subtraction. Fifth, because the core angiographic laboratory evaluated primarily DSA images, although stent proximal and distal markers could usually be visualized, stent struts could not be directly visualized. Given recent reports of increased delayed thromboembolic complications arising in cases in which stents do not fully appose the wall of the parent artery, ${ }^{22,23}$ this also limits our ability to evaluate delayed ischemic risk in stent-coiled patients.

\section{CONCLUSIONS}

Stent-coiling had outcomes similar to coiling, despite stented aneurysms having more difficult morphology than did coiled aneurysms. Increased ischemic events in stent-coiled aneurysms were attributable to baseline risk factors and aneurysm morphology, underscoring the overall safety of the stent-coiling technique. 


\section{ACKNOWLEDGMENTS}

The authors would like to thank Mary Farrant, Dean Menegaz, and Olivia Lam of University of California, San Francisco for their assistance in the MAPS angiographic core laboratory. The MAPS Trial was funded by Stryker Neurovascular and its predecessor Boston Scientific Neurovascular.

Disclosures: Steven Hetts—RELATED: Grant: Stryker Neurovascular and its predecessor Boston Scientific Neurovascular paid for the MAPS Trial, including the Core Angiographic Laboratory at UCSF*; UNRELATED: Board membership: ChemoFilter Inc, Comments: Scientific advisory board compensated through equity; Consultancy: Stryker Neurovascular, Penumbra, Silk Road Medical, Consultancy paid in cash; Grants/grants pending: $\mathrm{NIH}-\mathrm{NIBIB},{ }^{*}$ ASNR Foundation, ${ }^{*}$ Comments: R01 grant to develop magnetic catheter system; ASNR Scholar grant to develop magnetic catheter system; Patents (planned, pending, or issued): UCSF, ${ }^{*}$ Comments: Patents pending through UCSF on chemotherapy filtration system; Stock/stock options: Medina Medical, Comments: Scientific advisory board compensated through equity. Aquilla Turk-RELATED: Grant: MUSC from Stryker, Comments: Clinical trial; Consulting fee or honorarium: Stryker; UNRELATED: Board membership: Stryker; Consultancy: Stryker; Grants/grants pending: MUSC from Stryker.* Joey English—UNRELATED: Consultancy: Silk Road Medical, Stryker Neurovascular, Comments: I have done consultant work for a small start-up biotech company called Silk Road Medical and also for Stryker Neurovascular (the latter regarding their stent retriever device, Trevo). I have not done any consulting regarding aneurysm stents or coils; Expert testimony: I have previously served as an expert witness on medical-legal issues, but none currently and none regarding endovascular treatment of aneurysms. Christopher Dowd-RELATED: Fees for participation in review activities, such as data monitoring boards, statistical analysis, endpoint committees, and the like: Stryker, Comments: I served as Chief Adjudicator (blinded) for MAPS Trial. Charles Prestigiacomo- RELATED: Fees for participation in review activities, such as data monitoring boards, statistical analysis, endpoint committees, and the like: Stryker Clinical Events Committee; UNRELATED: Consultancy: Aesculap, Thermopeutix; Other: Edge Therapeutics, IBRF, Comments: Edge Therapeutics Scientific Advisory Board, no pay; IBRF board member, no pay. Sijian (Grace) Ge-RELATED: Fees for participation in review activities, such as data monitoring boards, statistical analysis, endpoint committees, and the like/payment for writing or reviewing the manuscript/other: I am a full-time employee as a statistician of Stryker. I am providing the professional biostatistical support to the analysis and result interpretations in this submission; UNRELATED: Employment: Senior Manager of Biostat \& CDM, Comments: see "Related" section for details regarding Stryker employment. Yuichi Murayama—UNRELATED: Consultancy: Stryker, Asahi Intecc; grants/grants pending: Siemens, ${ }^{\star}$ FujiFilm*; payment for lectures (including service on speakers bureaus): Stryker, Covidien; Patents (planned, pending, or issued): UCSF; royalties: Stryker. Anil Gholkar—RELATED: Grant: Stryker Neurovascular, Comments: Small grant for each patient recruited in the MAPS study, for the purpose of collecting and entering patient data into the study; Support for travel to meetings for the study or other purposes: Stryker Neurovascular, Comments: Support for travel to MAPS investigator meetings; UNRELATED: Consultancy: Codman Neurovascular, J\&J, Comments: Act as a consultant to deliver educational meetings; courses for interventional trainees; Travel/accommodations/meeting expenses unrelated to activities listed: Stryker Neurovascular (to SNIS), MicroVention (to WFITN), Comments: Have received support for attending above meetings from various device manufacturing companies; Other: Part funding for trainee, Comments: In the past, Stryker Neurovascular (Boston Scientific) provided part funding for interventional trainee at our institute. As far as I am aware, this was stopped several years ago. Demetrius Lopes- UNRELATED: Consultancy: Stryker; Payment for lectures (including service on speakers bureaus): Stryker; Payment for development of educational presentations: Stryker; Other: Stryker, Comments: Training program for new hires. S. Claiborne Johnston—RELATED: Grant: Stryker, ${ }^{*}$ Comments: Underlying support for the trial. Cameron McDougallUNRELATED: Consultancy: Covidien (ev3), Terumo (MicroVention), Comments: Scientific advisory panel for Covidien and proctor for eV3, consultant for MicroVention. Kristen Carroll-UNRELATED: Employment: I am a salaried employee of Stryker Corporation; stock/stock options: I have received stock options and grants as an employee of Stryker Corporation ('money paid to institution).

\section{REFERENCES}

1. Molyneux AJ, Kerr RS, Yu LM, et al. International Subarachnoid Aneurysm Trial (ISAT) of neurosurgical clipping versus endovascular coiling in 2143 patients with ruptured intracranial aneurysms: a randomised comparison of effects on survival, dependency, seizures, rebleeding, subgroups, and aneurysm occlusion. Lancet 2005;366:809-17

2. Wiebers DO, Whisnant JP, Huston J 3rd, et al. Unruptured intracra- nial aneurysms: natural history, clinical outcome, and risks of surgical and endovascular treatment. Lancet 2003;362:103-10

3. Raymond J, Guilbert F, Weill A, et al. Long-term angiographic recurrences after selective endovascular treatment of aneurysms with detachable coils. Stroke 2003;34:1398-403

4. Fiorella D, Albuquerque FC, Han P, et al. Preliminary experience using the Neuroform stent for the treatment of cerebral aneurysms. Neurosurgery 2004;54: 6-16

5. Higashida RT, Halbach VV, Dowd CF, et al. Initial clinical experience with a new self-expanding nitinol stent for the treatment of intracranial cerebral aneurysms: the Cordis Enterprise stent. AJNR Am J Neuroradiol 2005;26:1751-56

6. Sedat J, Chau Y, Mondot L, et al. Endovascular occlusion of intracranial wide-necked aneurysms with stenting (Neuroform) and coiling: midterm and long-term results. Neuroradiology 2009;51:401-09

7. Raslan AM, Oztaskin M, Thompson EM, et al. Neuroform stentassisted embolization of incidental anterior communicating artery aneurysms: long-term clinical and angiographic follow-up. Neurosurgery 2011;69: 27-37

8. Benitez RP, Silva MT, Klem J, et al. Endovascular occlusion of widenecked aneurysms with a new intracranial microstent (Neuroform) and detachable coils. Neurosurgery 2004;54:1359-67

9. Fiorella D, Albuquerque FC, Woo H, et al. Neuroform stent assisted aneurysm treatment: evolving treatment strategies, complications and results of long term follow-up. J Neurointerv Surg 2010;2:16-22

10. Fargen KM, Hoh BL, Welch BG, et al. Long-term results of Enterprise stent-assisted coiling of cerebral aneurysms. Neurosurgery 2012;71:239-44

11. Santillan A, Greenberg E, Patsalides A, et al. Long-term clinical and angiographic results of Neuroform stent-assisted coil embolization in wide-necked intracranial aneurysms. Neurosurgery 2012;70:1232-37

12. Lawson MF, Newman WC, Chi YY, et al. Stent-associated flow remodeling causes further occlusion of incompletely coiled aneurysms. Neurosurgery 2011;69:598-603

13. Brooks NP, Turk AS, Niemann DB, et al. Frequency of thromboembolic events associated with endovascular aneurysm treatment: retrospective case series. J Neurosurg 2008;108:1095-100

14. Piotin M, Blanc R, Spelle L, et al. Stent-assisted coiling of intracranial aneurysms: clinical and angiographic results in 216 consecutive aneurysms. Stroke 2010;41:110-15

15. Raymond JPM, White PM, Molyneux AJ. Scales, agreement, outcome measures, and progress in aneurysm therapy. AJNR Am J Neuroradiol 2007;28:501-02

16. Tollard E, Darsaut TE, Bing F, et al. Outcomes of endovascular treatments of aneurysms: observer variability and implications for interpreting case series and planning randomized trials. AJNR Am J Neuroradiol 2012;33:626-31

17. Cloft HJ, Kaufmann T, Kallmes DF. Observer agreement in the assessment of endovascular aneurysm therapy and aneurysm recurrence. AJNR Am J Neuroradiol 2007;28:497-500

18. Raymond J, Salazkin I, Georganos S, et al. Endovascular treatment of experimental wide-neck aneurysms: comparison of results using coils or cyanoacrylate with the assistance of an aneurysm neck bridge device. AJNR Am J Neuroradiol 2002;23:1710-16

19. Crobeddu E, Lanzino G, Kallmes DF, et al. Review of 2 decades of aneurysm-recurrence literature, part 1 . Reducing recurrence after endovascular coiling. AJNR Am J Neuroradiol 2013;34:266-70

20. Bendok BR, Hanel RA, Hopkins LN. Coil embolization of intracranial aneurysms. Neurosurgery 2003;52:1125-30

21. Fiorella D, Thiabolt L, Albuquerque FC, et al. Antiplatelet therapy in neuroendovascular therapeutics. Neurosurg Clin NAm 2005;16:517-40

22. Heller RS, Miele WR, Do-Dai DD, et al. Crescent sign on magnetic resonance angiography revealing incomplete stent apposition: correlation with diffusion-weighted changes in stent-mediated coil embolization of aneurysms. J Neurosurg 2011;115:624-32

23. Heller R, Calnan DR, Lanfranchi M, et al. Incomplete stent apposition in Enterprise stent-mediated coiling of aneurysms: persistence over time and risk of delayed ischemic events. J Neurosurg 2013;118:1014-22 